Jurnal Matematika UNAND

Vol. IX No. 1 Hal. $38-45$

Edisi Januari 2020

ISSN : 2303-291X

(C)Jurusan Matematika FMIPA UNAND

\title{
GRAF LEMBUT KABUR
}

\author{
ANGGUN DELVIANA* NARWEN \\ Program Studi S1 Matematika, \\ Fakultas Matematika dan Ilmu Pengetahuan Alam, Universitas Andalas, \\ Kampus UNAND Limau Manis Padang, Indonesia. \\ email : anggundelvi@gmail.com,narwen@sci.unand.ac.id
}

\begin{abstract}
Abstrak. Pada penelitian ini dibahas beberapa jenis graf lembut kabur dan hubungan antara graf-graf lembut kabur tersebut, yang diantaranya yaitu graf lembut kabur, graf lembut kabur reguler, graf lembut kabur total reguler, dan graf lembut kabur parsial reguler.

Kata Kunci: Graf lembut kabur, graf lembut kabur reguler, graf lembut kabur total reguler, graf lembut kabur parsial reguler
\end{abstract}

\section{Pendahuluan}

Teori himpunan kabur (fuzzy set) pertama kali diperkenalkan oleh Dr. L. A Zadeh pada tahun 1965 [11]. Himpunan kabur memiliki nilai keanggotaan yang berada pada interval $[0,1]$. Pada kehidupan nyata sering ditemukan kasus yang mengandung unsur ketidakpastian, oleh karena itu masalah ketidakpastian ini dapat diselesaikan dengan teori himpunan kabur. Pada tahun 1999 Molodstov [8] memperkenalkan himpunan lembut (soft set). Selanjutnya diperkenalkan himpunan lembut kabur (fuzzy soft set) oleh Maji dkk pada tahun 2001 [7]. Babitha dan Sunil memperkenalkan konsep relasi dan fungsi pada teori himpunan lembut[3]. Sedangkan Roy dan Maji memperkenalkan beberapa penggunaan himpunan lembut kabur dalam pengambilan keputusan [9].

Konsep graf kabur pertama kali diperkenalkan oleh Kaufmaan pada tahun 1973 [2]. Bhattacharya memberikan beberapa catatan pada Graf Kabur [4]. Thumbakara dan George mendiskusikan konsep graf lembut dengan cara yang lebih spesifik [10]. Akram dan Nawaz memperkenalkan konsep graf lembut, induksi titik, dan induksi sisi graf lembut pada tahun 2015 [2]. Pada penelitian ini akan dikaji suatu konsep yang merupakan gabungan dari konsep graf kabur dan graf lembut yang merupakan kajian kembali dari artikel Akram dan Nawaz [1].

*penulis korespondensi 


\section{Landasan Teori}

\subsection{Himpunan Lembut, Himpunan Kabur, Himpunan Lembut Kabur}

Definisi 2.1. [8] Misalkan $U$ adalah himpunan semesta, $P(U)$ adalah suatu himpunan kuasa atas $U, E$ adalah himpunan parameter. Pasangan $(F, E)$ disebut suatu himpunan lembut atas $U$ jika dan hanya jika $F$ adalah pemetaan dari $E$ ke $P(U)$, yang dapat dinyatakan sebagai pasangan terurut yang berbentuk

$$
(F, E)=\{(e, F(e)) \mid e \in E, F(e) \in P(U)\} .
$$

Definisi 2.2. [11] Misalkan $X$ adalah suatu himpunan semesta yang tak kosong. Suatu himpunan kabur $A$ atas $X$ didefinisikan sebagai

$$
A=\left\{\left(x, \mu_{A}(x)\right) \mid x \in X\right\},
$$

dimana $\mu_{A}: X \rightarrow[0,1]$, dan $\mu_{A}(x)$ disebut nilai keanggotaan atas $x$ pada himpunan kabur A.

Definisi 2.3. [7] Misalkan $U$ adalah himpunan semesta, $F(U)$ adalah himpunan dari seluruh himpunan kabur atas $U, E$ adalah suatu himpunan parameter, $A \subseteq E$. Pasangan $(\tilde{F}, A)$ disebut himpunan lembut kabur, dengan $\tilde{F}$ adalah pemetaan dari $A$ ke $F(U)$ yang dapat dinyatakan sebagai pasangan terurut yang berbentuk,

$$
(\tilde{F}, A)=\{(a, \tilde{F}(a)) \mid a \in A, \tilde{F}(a) \in F(U)\}=\{(a,\{(x, \tilde{F}(a)(x) \mid x \in U\}) \mid a \in A\} .
$$

Dalam hal ini, $\tilde{F}(a)(x)$ adalah nilai keanggotaan dari $x$ yang bersesuaian dengan parameter $a$.

\subsection{Graf}

Pada subbab ini akan dibahas beberapa istilah pada graf yang dikutip dari [5]. Sebuah graf $G^{*}$ yang dalam hal ini disebut graf tegas didefinisikan sebagai himpunan pasangan terurut $G^{*}=\left(V\left(G^{*}\right), E\left(G^{*}\right)\right)$ dimana $V\left(G^{*}\right)$ adalah himpunan titik yang tak kosong dan $E\left(G^{*}\right)$ adalah himpunan sisi-sisi. Banyak titik pada graf $G^{*}$ disebut orde, dan banyak sisi pada graf $G^{*}$ disebut size.

Dua titik $u$ dan $v$ di graf tegas $G^{*}$ dikatakan bertetangga (adjacent) jika titik $u$ dan $v$ terhubung oleh suatu sisi. Derajat dari titik $v$ di $G^{*}$ adalah jumlah sisi yang terkait dengan titik $v$. Sebuah graf tegas dikatakan reguler jika setiap titik memiliki derajat yang sama. Graf cycle $C_{m}$ merupakan graf tegas terhubung yang mempunyai $m$ titik yang setiap titiknya berderajat dua, untuk $m \geq 3$. Loop adalah suatu sisi yang memiliki titik awal dan titik akhir sama. Sisi ganda adalah dua titik yang dihubungkan oleh dua sisi yang berbeda. Graf sederhana adalah graf tegas yang tidak memuat loop dan sisi ganda.

\subsection{Graf Kabur, Graf Lembut, dan Graf Lembut Kabur}

Definisi 2.4. [1] Graf kabur $G^{\prime}=(\mu, \gamma)$ pada graf tegas $G^{*}=(V, E)$ adalah pasangan dari fungsi $\mu: V \rightarrow[0,1]$ dan $\gamma: V \times V \rightarrow[0,1], \forall u, v \in V$, dimana $\gamma(u$, $v) \leq \min (\mu(u), \mu(v)), \forall u, v \in V$. 
Definisi 2.5. [2] Sebuah graf lembut adalah 4-urutan $G=\left(G^{*}, F, K, A\right)$ memenuhi sebagai berikut:

(a) $G^{*}=(V, E)$ adalah graf sederhana.

(b) A adalah himpunan tak kosong dari parameter-parameter.

(c) $(F, A)$ adalah himpunan lembut atas $V$.

(d) $(K, A)$ adalah himpunan lembut atas $E$.

(e) $(F(a), K(a))$ adalah subgraf tegas dari $G^{*}$ untuk semua $a \in A$.

Definisi 2.6. [1] Sebuah graf lembut kabur adalah 4-urutan $\tilde{G}=\left(G^{*}, \tilde{F}, \tilde{K}, A\right)$ yang memenuhi sebagai berikut:

(a) $G^{*}=(V, E)$ adalah graf sederhana.

(b) A adalah himpunan tak kosong dari parameter-parameter.

(c) $(\tilde{F}, A)$ adalah himpunan lembut kabur atas $V$, dengan $\tilde{F}$ adalah suatu fungsi $\tilde{F}: A \rightarrow \tilde{P}(V), \tilde{P}(V)$ adalah kumpulan himpunan kabur atas $V$.

(d) $(\tilde{K}, A)$ adalah himpunan lembut kabur atas $E$, dengan $\tilde{K}$ adalah suatu fungsi $\tilde{K}: A \rightarrow \tilde{P}(E), \tilde{P}(E)$ adalah kumpulan himpunan kabur atas $E$.

(e) $(\tilde{F}(a), \tilde{K}(a))$ adalah subgraf kabur dari $G^{*}$ untuk semua a $\in$ A, yaitu $\tilde{K}(a)(x y) \leq \min \{\tilde{F}(a)(x), \tilde{F}(a)(y)\}$, untuk setiap $a \in A$ dan $x, y \in V$. Graf Kabur $(\tilde{F}(a), \tilde{K}(a))$ dinotasikan dengan $\tilde{H}(a)$.

\section{Graf Lembut Kabur}

\subsection{Beberapa Definisi pada Graf Kabur}

Pada subbab ini dibahas beberapa definisi terkait graf kabur yaitu graf kabur kuat, order, size, derajat titik, derajat total pada graf kabur, graf kabur reguler, graf kabur total reguler, dan graf kabur parsial reguler.

Definisi 3.1. [1] $G^{\prime}=(\mu, \gamma)$ adalah graf kabur pada $G^{*}=(V, E)$. Sebuah Graf Kabur $G^{\prime}=(\mu, \gamma)$ dikatakan graf kabur kuat jika $\gamma(u, v)=\min (\mu(u), \mu(v))$, $\forall(u, v) \in E$.

Definisi 3.2. [1] $G^{\prime}=(\mu, \gamma)$ adalah graf kabur pada $G^{*}=(V, E)$. Orde dari graf kabur $G^{\prime}=(\mu, \gamma)$ adalah $O\left(G^{\prime}\right)=\sum_{u \in V} \mu(u)$.

Definisi 3.3. [1] $G^{\prime}=(\mu, \gamma)$ adalah graf kabur dari $G^{*}=(V, E)$. Size dari graf kabur adalah $S\left(G^{\prime}\right)=\sum_{(u, v) \in E} \gamma(u, v)$.

Definisi 3.4. [1] $G^{\prime}=(\mu, \gamma)$ adalah graf kabur pada $G^{*}=(V, E)$.

Derajat dari titik $u$ di $G^{\prime}=(\mu, \gamma)$ adalah deg $(u)=\sum_{u \neq v} \gamma(u, v)=\sum_{u v \in E} \gamma(u, v)$.

Definisi 3.5. [1] Misalkan $G^{\prime}=(\mu, \gamma)$ adalah graf kabur pada $G^{*}=(V, E)$. Derajat total dari sebuah titik $u$ di $V$ adalah $\operatorname{tdeg}(u)=\mu(u)+\sum_{u v \in E} \gamma(u, v)=\mu(u)+\operatorname{deg}(u)$.

Definisi 3.6. [1] $G^{\prime}=(\mu, \gamma)$ adalah sebuah graf kabur pada $G^{*}=(V, E)$. $G^{\prime}=(\mu, \gamma)$ dikatakan reguler jika setiap titik pada graf kabur memiliki derajat yang sama.

Definisi 3.7. [1] $G^{\prime}=(\mu, \gamma)$ adalah sebuah graf kabur pada $G^{*}=(V, E) . G^{\prime}=(\mu, \gamma)$ dikatakan total reguler jika setiap titik memiliki derajat total yang sama. 
Definisi 3.8. [1] Jika graf $G^{*}$ adalah reguler, maka $G^{\prime}$ dikatakan graf kabur parsial regular.

\subsection{Beberapa Jenis Graf Lembut Kabur}

Pada subbab ini dibahas beberapa jenis graf lembut kabur dan hubungan antara graf-graf tersebut.

Definisi 3.9. [1] Orde dari sebuah graf lembut kabur adalah $\operatorname{Ord}(\tilde{G})=\sum_{e_{i} \in A}\left(\sum_{a \in V} \tilde{F}\left(e_{i}\right)(a)\right)$.

Definisi 3.10. [1] Size dari sebuah graf lembut kabur adalah $\operatorname{Siz}(\tilde{G})=\sum_{e_{i} \in A}\left(\sum_{a b \in E} \tilde{K}\left(e_{i}\right)(a b)\right)$.

Definisi 3.11. [1] Misal $G^{*}=(V, E)$ adalah sebuah graf tegas dan $\tilde{G}$ adalah graf lembut kabur dari $G^{*}$. Sebuah $\tilde{G}$ dikatakan graf lembut kabur reguler jika $\tilde{H}(e)$ adalah graf kabur reguler,$\forall e \in A$. Jika $\tilde{H}(e)$ adalah graf kabur reguler dengan derajat $r$ maka $\tilde{G}$ adalah graf lembut kabur reguler-r.

Definisi 3.12. [1] Misal $G^{*}=(V, E)$ adalah sebuah graf tegas, dan $\tilde{G}$ adalah graf lembut kabur dari $G^{*}$. Sebuah $\tilde{G}$ dikatakan graf lembut kabur total reguler jika $\tilde{H}(e)$ adalah graf kabur total reguler, $\forall e \in A$. Jika $\tilde{H}(e)$ adalah graf kabur total reguler yang mempunyai derajat total $r$, maka $\tilde{G}$ adalah graf lembut kabur total reguler-r.

Definisi 3.13. [1] Misal $\tilde{G}$ adalah graf lembut kabur atas $G^{*}$. Sebuah $\tilde{G}$ dikatakan graf lembut kabur parsial reguler jika $\tilde{H}(e)$ adalah graf kabur parsial reguler, untuk setiap $e \in A$.

Teorema 3.14. [1] Misal $G^{*}=(V, E)$ adalah sebuah graf sederhana dan $\tilde{G}$ adalah graf lembut kabur dari $G^{*}$. Jika $\tilde{G}$ adalah graf lembut kabur reguler dan $\tilde{F}$ adalah sebuah fungsi konstan di graf kabur $\tilde{H}\left(e_{i}\right)$ dari $G^{*}, \forall e_{i} \in A$, untuk $i=1,2, . ., n$, maka $\tilde{G}$ adalah graf lembut kabur total regular.

Bukti. Misalkan $\tilde{G}$ adalah graf lembut kabur reguler, maka $\operatorname{deg}(a)=r_{i}, \forall a \in V$, $e_{i} \in A$, untuk $i=1,2, \cdots, n$. Misalkan $\tilde{F}$ adalah fungsi konstan, maka $\tilde{F}\left(e_{i}\right)(a)=$ $c_{i}, c_{i}$ adalah kosntan, $c_{i} \in[0.1]$. Perhatikan bahwa

$$
\operatorname{tdeg}(a)=\operatorname{deg}(a)+\tilde{F}\left(e_{i}\right)(a)=r_{i}+c_{i},
$$

di graf kabur $\tilde{H}\left(e_{i}\right) \forall a \in V, \forall e_{i} \in A$, untuk $i=1,2, \cdots, n$, maka $\tilde{G}$ adalah graf lembut kabur total reguler.

Teorema 3.15. [1] Misal $G^{*}=(V, E)$ adalah sebuah graf tegas dan $\tilde{G}$ adalah graf lembut kabur dari $G^{*}$. Jika $\tilde{G}$ adalah graf lembut kabur total reguler dan $\tilde{F}$ adalah sebuah fungsi konstan di graf kabur $\tilde{H}\left(e_{i}\right)$ dari $G^{*}, \forall e_{i} \in A$, untuk $i=1,2, . ., n$, maka $\tilde{G}$ adalah graf lembut kabur reguler.

Bukti. Misalkan $\tilde{G}$ adalah graf lembut kabur total reguler, maka $\operatorname{tdeg}(a)=r_{i}$, di $\tilde{H}\left(e_{i}\right) \forall a \in V, e_{i} \in A$, untuk $i=1,2, \cdots, n$. Misalkan $\tilde{F}$ adalah fungsi konstan, maka 
$\tilde{F}\left(e_{i}\right)(a)=c_{i}, c_{i}$ adalah kosntan, $c_{i} \in[0.1], \forall a \in V, \forall e_{i} \in A$, untuk $i=1,2, \cdots, n$. Perhatikan bahwa:

$$
\operatorname{deg}(a)=\operatorname{tdeg}(a)-\tilde{F}\left(e_{i}\right)(a)=r_{i}-c_{i},
$$

di graf kabur $\tilde{H}\left(e_{i}\right) \forall a \in V, \forall e_{i} \in A$, untuk $i=1,2, \cdots, n$. Sehingga $\tilde{G}$ adalah graf lembut kabur reguler .

Teorema 3.16. [1] Jika $\tilde{G}$ adalah graf lembut kabur reguler dan total reguler, maka $\tilde{F}$ adalah fungsi konstan di $\tilde{H}\left(e_{i}\right)$ dari $G^{*} \forall e_{i} \in A$, untuk $i=1,2, \cdots, n$.

Bukti. Misalkan $\tilde{G}$ adalah graf lembut kabur reguler, maka $\operatorname{deg}(a)=r_{i} \operatorname{dan} \tilde{G}$ adalah graf lembut kabur total reguler, maka $\operatorname{tdeg}(a)=s_{i}$. Perhatikan bahwa:

$$
\begin{aligned}
\operatorname{deg}(a)+\tilde{F}\left(e_{i}\right)(a) & =\operatorname{tdeg}(a), \\
\operatorname{deg}(a)+\tilde{F}\left(e_{i}\right)(a) & =s_{i}, \\
r_{i}+\tilde{F}\left(e_{i}\right)(a) & =s_{i}, \\
\tilde{F}\left(e_{i}\right)(a) & =s_{i}-r_{i},
\end{aligned}
$$

di $\tilde{H}\left(e_{i}\right)$ dari $G^{*}, \forall e_{i} \in A$, untuk $i=1,2, \cdots, n \forall a \in V$. Akibatnya $\tilde{F}$ adalah fungsi konstan pada $\tilde{H}\left(e_{i}\right), \forall e_{i} \in A$, untuk $i=1,2, \cdots, n$.

Teorema 3.17. [1] Misal $\tilde{G}$ adalah graf lembut kabur atas cycle ganjil $G^{*}=(V, E)$. Sebuah $\tilde{G}$ adalah graf lembut kabur reguler jika dan hanya jika $\tilde{K}$ adalah fungsi konstan di graf kabur $\tilde{H}\left(e_{i}\right)$ atas $H^{*}\left(e_{i}\right)$, dimana $H^{*}\left(e_{i}\right)$ adalah cycle ganjil, $\forall e_{i} \in$ $A$ untuk $i=1,2, \cdots, n$.

Bukti. $(\Rightarrow)$ Misalkan $\tilde{G}$ adalah graf lembut kabur reguler, akan ditunjukkan $\tilde{K}$ adalah fungsi konstan di subgraf kabur $\tilde{H}\left(e_{i}\right)$ atas $H^{*}\left(e_{i}\right)$, dimana $H^{*}\left(e_{i}\right)$ adalah cycle ganjil, $\forall e_{i} \in A, i=1,2,3, \cdots, n$. Misalkan $\tilde{G}$ adalah graf lembut kabur reguler dari $G^{*}$, maka $\operatorname{deg}(a)=s_{i}$ di $\tilde{H}\left(e_{i}\right)$. Misalkan $d_{1}, d_{2}, d_{3}, \cdots, d_{2 n+1}$ adalah sisi-sisi dari $G^{*}$ yang berurutan. Misal

$$
\begin{aligned}
\tilde{K}\left(e_{i}\right)\left(d_{1}\right) & =r_{i}, \quad \text { di } \tilde{H}\left(e_{i}\right), \forall e_{i} \in A, \text { untuk } i=1,2, \cdots, n . \\
\operatorname{deg}(a) & =\tilde{K}\left(e_{i}\right)\left(d_{1}\right)+\tilde{K}\left(e_{i}\right)\left(d_{2}\right), \\
s_{i} & =r_{i}+\tilde{K}\left(e_{i}\right)\left(d_{2}\right), \\
\tilde{K}\left(e_{i}\right)\left(d_{2}\right) & =s_{i}-r_{i}, \\
\tilde{K}\left(e_{i}\right)\left(d_{3}\right) & =s_{i}-\left(s_{i}-r_{i}\right)=r_{i}, \\
\tilde{K}\left(e_{i}\right)\left(d_{j}\right) & = \begin{cases}r_{i}, & \text { jika } j \text { ganjil } \\
s_{i}-r_{i}, & \text { jika } j \text { genap. }\end{cases}
\end{aligned}
$$

Jadi $\tilde{K}\left(e_{i}\right)\left(d_{1}\right)=\tilde{K}\left(e_{i}\right)\left(d_{2 n+1}\right)=r_{i} \forall e_{i} \in A$ untuk $i=1,2, \cdots, n$. Jika $d_{1}$ dan $d_{2 n+1}$ terkait pada titik $v$, maka $\operatorname{deg}(v)=s_{i}$ di graf kabur $\tilde{H}\left(e_{i}\right)$. Sehingga diperoleh $\tilde{K}\left(e_{i}\right)\left(d_{1}\right)+\tilde{K}\left(e_{i}\right)\left(d_{2 n+1}\right)=s_{i}$ di $\tilde{H}\left(e_{i}\right) \forall e_{i} \in A$ untuk $i=1,2, \cdots, n$. Perhatikan 
bahwa

$$
\begin{aligned}
\tilde{K}\left(e_{i}\right)\left(d_{1}\right)+\tilde{K}\left(e_{i}\right)\left(d_{2 n+1}\right) & =s_{i}, \\
r_{i}+r_{i} & =s_{i}, \\
2 r_{i} & =s_{i}, \\
r_{i} & =\frac{s_{i}}{2}, \\
s_{i}-r_{i} & =s_{i}-\frac{s_{i}}{2}=\frac{s_{i}}{2} .
\end{aligned}
$$

Diperoleh $\tilde{K}\left(e_{i}\right)\left(d_{j}\right)=\frac{s_{i}}{2}$ di graf kabur $\tilde{H}\left(e_{i}\right), \forall e_{i} \in A$ untuk $i=1,2, \cdots, n$, sehingga $\tilde{K}$ adalah fungsi konstan.

$(\Longleftarrow)$ Misalkan $\tilde{K}$ adalah fungsi konstan di graf kabur $\tilde{H}\left(e_{i}\right)$ atas $\tilde{H}^{*}\left(e_{i}\right)$ adalah cycle ganjil, akan ditunjukkan $\tilde{G}$ adalah graf lembut kabur reguler. Misalkan $\tilde{K}$ adalah fungsi konstan, maka $\tilde{K}\left(e_{i}\right)(a b)=c_{i}, c_{i} \in[0.1], \forall e_{i} \in A$, untuk $i=1,2, \cdots, n$, di graf kabur $\tilde{H}\left(e_{i}\right), \forall a b \in E$. Jadi $\operatorname{deg}(a)=2 c_{i}$, di graf kabur $\tilde{H}\left(e_{i}\right), \forall a \in V$. Sehingga $\tilde{G}$ adalah graf lembut kabur reguler.

Teorema 3.18. [1] Suatu graf lembut kabur reguler $\tilde{G}$ atas $G^{*}$ dengan $|V| \geq 3$ dan $\tilde{H}\left(e_{i}\right)$ adalah graf kabur reguler dengan derajat $s_{i}>0$, untuk $i=1,2, \cdots, n$, tidak mempunyai titik akhir.

Bukti. Misalkan $\tilde{H}\left(e_{i}\right)$ adalah graf kabur reguler dengan derajat $s_{i}$, maka $\operatorname{deg}(a)=$ $s_{i}, \forall a \in V, e_{i} \in A, i=1,2, \cdots, n$. Misalkan $s_{i}>0$, maka $\operatorname{deg}(a)>0, \forall a \in V$, sehingga setiap titik adalah bertetangga dengan titik lain.

Dengan kontradiksi, misalkan $b$ adalah titik akhir. Selanjutnya dipeoleh $\operatorname{deg}(b)=$ $s_{i}=\tilde{K}\left(e_{i}\right)(a b)$ di $\tilde{H}\left(e_{i}\right)(a b)$. Misalkan $\tilde{H}\left(e_{i}\right)$ adalah graf kabur reguler dengan $|V| \geq 3$, untuk $i=1,2, \cdots, n$, maka $a$ harus adjacent dengan ke titik $c \neq b$. Perhatikan bahwa

$$
\operatorname{deg}(a)=\tilde{K}\left(e_{i}\right)(a b)+\tilde{K}\left(e_{i}\right)(a c)>\tilde{K}\left(e_{i}\right)(a b)
$$

di graf kabur $\tilde{H}\left(e_{i}\right)$, untuk $i=1,2, \cdots, n$, maka $\operatorname{deg}(a)>s_{i}$ di $\tilde{H}\left(e_{i}\right)$, yang mana kontradiksi dengan $\tilde{H}\left(e_{i}\right)$ adalah graf kabur reguler dengan derajat $s_{i}$, untuk $i=$ $1,2, \cdots, n$, sehingga $\tilde{G}$ tidak memiliki titik akhir.

Teorema 3.19. [1] Misal $\tilde{G}$ adalah graf lembut kabur dan $\tilde{K}$ adalah fungsi konstan di $\tilde{H}\left(e_{i}\right), \forall e_{i} \in A$, untuk $i=1,2, \cdots, n$. Suatu $\tilde{G}$ adalah graf lembut kabur reguler jika dan hanya jika $\tilde{G}$ adalah graf lembut kabur parsial reguler.

Bukti. Misalkan $\tilde{K}\left(e_{i}\right)(a b)=c_{i}, c_{i} \in[0,1], c_{i}$ adalah konstan $\forall a b \in E, \forall e_{i} \in A$, untuk $i=1,2, \cdots, n$.

$(\Rightarrow)$ Misalkan $\tilde{G}$ adalah graf lembut kabur reguler, akan ditunjukkan $\tilde{G}$ adalah graf lembut kabur parsial reguler . 
Misalkan $\tilde{G}$ adalah graf lembut kabur reguler, maka

$$
\begin{aligned}
\operatorname{deg}_{\tilde{H}\left(e_{i}\right)}(a) & =\sum_{a b \in E} \tilde{K}\left(e_{i}\right)(a b)=\sum_{a b \in E} c_{i}=c_{i} \operatorname{deg}_{H^{*}\left(e_{i}\right)}(a), \\
& =t_{i}, \\
\operatorname{deg}_{H^{*}\left(e_{i}\right)}(a) & =\frac{t_{i}}{c_{i}}, \forall a \in V, e_{i} \in A, \text { untuk } i=1,2, \cdots, n .
\end{aligned}
$$

Sehingga diperoleh $H^{*}\left(e_{i}\right)$ adalah graf reguler $\forall e_{i} \in A$, untuk $i=1,2, \cdots, n$. Akibatnya $\tilde{H}\left(e_{i}\right)$ adalah graf kabur parsial reguler. Jadi $\tilde{G}$ adalah graf lembut kabur parsial reguler.

$(\Longleftarrow)$ Misalkan $\tilde{G}$ adalah graf lembut kabur parsial reguler, akan ditunjukkan $\tilde{G}$ adalah graf lembut kabur reguler. Misalkan $\tilde{G}$ adalah graf lembut kabur parsial reguler. Misalkan $H^{*}\left(e_{i}\right)$ adalah graf reguler dengan derajat $s_{i}$. Perhatikan bahwa,

$$
\begin{aligned}
& \operatorname{deg}_{\tilde{H}\left(e_{i}\right)}(a)=c_{i} \operatorname{deg}_{H^{*}\left(e_{i}\right)}(a), \\
& \operatorname{deg}_{\tilde{H}\left(e_{i}\right)}(a)=c_{i} s_{i}, \forall a \in V, e_{i} \in A, \text { untuk } i=1,2, \cdots, n .
\end{aligned}
$$

Jadi $\tilde{G}$ adalah graf lembut kabur reguler .

Teorema 3.20. [1] Misalkan $\tilde{G}$ adalah graf lembut kabur kuat dan $\tilde{F}$ adalah fungsi konstan di $\tilde{H}\left(e_{i}\right)$. Sebuah $\tilde{G}$ adalah graf lembut kabur reguler jika dan hanya jika $\tilde{G}$ adalah graf lembut kabur parsial reguler.

Bukti. Misalkan $\tilde{F}$ adalah fungsi konstan, maka $\tilde{F}\left(e_{i}\right)=c_{i}$, dimana $c_{i}=[0.1]$, $\forall a \in V, e_{i} \in A$, untuk $i=1,2, \cdots, n$. Misalkan $\tilde{G}$ adalah graf lembut kabur kuat, maka $\tilde{H}\left(e_{i}\right)$ adalah graf kabur kuat, $\forall a \in V, e_{i} \in A$, untuk $i=1,2, \cdots, n$, berlaku $\tilde{K}\left(e_{i}\right)(a b)=\min \left(\tilde{F}\left(e_{i}\right)(a), \tilde{F}\left(e_{i}\right)(b)\right)=c_{i}, \forall a \in V, e_{i} \in A$, untuk $i=1,2, \cdots, n$, diperoleh $\tilde{K}$ adalah fungsi konstan.

$(\Rightarrow)$ Misalkan $\tilde{G}$ adalah graf lembut kabur reguler, akan ditunjukkan $\tilde{G}$ adalah graf lembut kabur parsial reguler. Misalkan $\tilde{G}$ adalah graf lembut kabur reguler, maka

$$
\begin{aligned}
\operatorname{deg}_{\tilde{H}\left(e_{i}\right)}(a) & =\sum_{a b \in E} \tilde{K}\left(e_{i}\right)(a b)=\sum_{a b \in E} c_{i}=c_{i} \operatorname{deg}_{H^{*}\left(e_{i}\right)}(a), \\
\operatorname{deg}_{\tilde{H}\left(e_{i}\right)}(a) & =c_{i} \operatorname{deg}_{H^{*}\left(e_{i}\right)}(a)=t_{i}, \\
\operatorname{deg}_{H^{*}\left(e_{i}\right)}(a) & =\frac{t_{i}}{c_{i}}, \forall a \in V, e_{i} \in A, \text { untuk } i=1,2, \cdots, n .
\end{aligned}
$$

Sehingga $H^{*}\left(e_{i}\right)$ adalah graf reguler $\forall e_{i} \in A$, untuk $i=1,2, \cdots, n$. Jadi $\tilde{H}\left(e_{i}\right)$ adalah graf kabur parsial reguler, sehingga $\tilde{G}$ adalah graf lembut kabur parsial reguler.

$(\Longleftarrow)$ Misalkan $\tilde{G}$ adalah graf lembut kabur parsial reguler, akan ditunjukkan $\tilde{G}$ adalah graf lembut kabur reguler. Misalkan $\tilde{G}$ adalah graf lembut kabur parsial reguler. Misalkan $H^{*}\left(e_{i}\right)$ adalah graf reguler dengan derajat $s_{i}$. Perhatikan bahwa,

$$
\begin{aligned}
& \operatorname{deg}_{\tilde{H}\left(e_{i}\right)}(a)=c_{i} \operatorname{deg}_{H^{*}\left(e_{i}\right)}(a), \\
& \operatorname{deg}_{\tilde{H}\left(e_{i}\right)}(a)=c_{i} s_{i}, \forall a \in V, e_{i} \in A, \text { untuk } i=1,2, \cdots, n .
\end{aligned}
$$


Jadi $\tilde{G}$ adalah graf lembut kabur reguler.

\section{Kesimpulan}

Misalkan diberikan suatu graf tegas $G^{*}$ dengan himpunan titik V dan himpunan sisi E. Dengan mendefinisikan suatu himpunan kabur, masing-masing atas $\mathrm{V}$ dan E maka akan diperoleh suatu graf kabur. Jika diberikan beberapa parameter dan masing-masingnya dikaitkan dengan suatu graf kabur, maka akan terbentuk suatu graf lembut kabur. Terkait dengan beberapa jenis graf lembut kabur, diperoleh beberapa syarat perlu dan atau syarat cukup, yaitu:

(a) Syarat cukup graf lembut kabur merupakan graf lembut kabur total reguler .

(b) Syarat cukup graf lembut kabur merupakan graf lembut kabur reguler.

(c) Syarat perlu graf lembut kabur merupakan graf lembut kabur reguler dan total reguler.

(d) Syarat perlu dan syarat cukup graf lembut kabur merupakan graf lembut kabur regular.

(e) Syarat perlu graf lembut kabur dengan $|V| \geq 3$ merupakan graf lembut kabur reguler.

(f) Syarat perlu dan syarat cukup graf lembut kabur merupakan graf lembut kabur parsial reguler.

\section{Daftar Pustaka}

[1] Akram,M dan Nawaz, S. 2015. On fuzzy soft graph. Italian Journal of pure and Applied Mathematics. $34: 497-514$

[2] Akram,M dan Nawaz, S. 2015. Operation on soft graphs. Fuzzy Information and Engineering. 7: 423 - 449

[3] Babitha, K.V, dan Sunil,J.J. 2010. Soft set relation and function. Computers and Mathematics with Application. 60 : 1840 - 1849

[4] Battacharya,P. 1987. Some remarks on fuzzy graphs. Pattern Recognition Letter. 5 : $297-302$

[5] Bondy, J.A dan Murty, U.S.R. 1976. Graph Theory with Application. The Macmillan Press LTD, London.

[6] Dusmanta Kumar Sut. 2012. An application of fuzzy soft set relation in decision making problem. International Journal of Mathematics Trends and Technology. $5: 50-53$.

[7] Maji, P.K, Biawas, R dan Roy, A.R. 2001. Fuzzy soft sets. Journal of Fuzzy Mathematics. 9: 589 - 602

[8] Molodtsov, D.A. 1999. Soft set theory-first results. Computers and Mathematics with Application. 37 : $19-31$

[9] Roy, A.R dan Maji,P.K. 2007. A fuzzy set theoretic approach to decision making problems. Journal of Computational and Applied Mathematics. 203 : $412-418$

[10] Thumbakara, R.K dan Georgeo, B. 2014. Soft graphs. General Mathematics notes. 2: $75-86$

[11] Zadeh, L.A. 1965. Fuzzy sets. Information and Computation. 8: 338 - 353 